\title{
HYBRID LAYER TYPE CR/LPC
}

\author{
Konrad Dybowski', Paulina Kowalczyk ${ }^{1}$, Bartłomiej Januszewicz' ${ }^{1}$ Damian Batory ${ }^{1}$ \\ 1 Institute of Materials Science \& Engineering, Technical University of Lodz, 1/15 Stefanowskiego Street, 90- \\ 924 Lodz, Poland, e-mail: paulina.kowalczyk@p.lodz.pl
}

Received: 2016.11 .28

Accepted: 2017.02 .07

Published: 2017.06.01

\begin{abstract}
Application of metal coatings and the carburized layer are widely known and readily used for various elements, depending on the application. Metal coatings based on chromium are used in order to increase resistance to wear, corrosion and erosion. The coatings applied by different methods have a significant drawback - they are not well related with the substratum, so there is a risk of cracking or flaking. Any discrepancies and flaws disqualify such a way as to protect the surface. Carburizing processes will be carried out, primarily in order to increase the hardness of the surface layer while maintaining a ductile core of the object. It is likely that the combination of these treatments will provide to increase the hardness of the material. The behavior of the proper order to create hybrid layer ensures the continuity of the resulting layer and its good connection with the steel. The paper presents a hybrid layer consisting of the deposited chrome and PVD in the next stage of low pressure carburizing. Conducted process allows chromium diffusion into the material, the enrichment of the steel and to ensure the continuity of the layer.
\end{abstract}

Keywords: hybrid layer, thermo-chemical treatment, metallization, diffusion.

\section{INTRODUCTION}

The formation of the hybrid layer is performed using a combination of different surface treatment processes. It is possible, for example, to create a layer consisting of carbides of various metals by a combination of metallization and carburization process. In this type of hybrid treatment processes PVD or CVD, and electrochemical methods are employed to apply a given element / elements to the surface of the workpiece. The applied element diffuses the thermo-chemical treatment, which can be, for example, carburizing $[4 \div 10,12,14,15]$. Combining metallization with thermo-chemical processes allows the formation of a continuous film of carbide, providing a good grip with the metal substrate. This type of hybrid layer may cause an increase in anti-wear properties and corrosion resistance of the workpiece $[14,15]$. At present literature reports about the use of combined treatments to produce anti-corrosion layers using carburizing process, after coating the steel with nickel and cobalt [12] and also uses of anti-wear, for example, by formation of chromium carbide on steel [11]. For increasing chromium carbide coatings, it is noted that in case of crystalline layers achieves higher hardness and a lower friction coefficient compared with amorphous coatings [3]. Preparation of hybrid layer may also dispense with the method TRD (thermal reactive deposition) using a directly applied coating of an intermetallic phase set, or a chemical compound [1]. Creating hybrid layers achieve the specified performance in surface area and good adhesion and continuity produced between the casing and the core of the work material. The combination of several surface treatments allows for an increase in mechanical properties, but also depends on the type of input element, which may increase the other physico-chemical properties. 
The article presents a new way of forming a hybrid layer, the method of combining RF-PVD with low pressure carburizing (LPC). The hybrid layer was made by that method, which is a combination of chromium with the carburization of the iron substrate. The conducted process allows a diffusion of chromium into the processed material, forming the basis of the intermetallic phases and continuity produced layer. The article presents metallographic layers made of hybrid, and $\mathrm{X}$-ray diffraction was performed to determine the construction phase. Studies were also made on carbon concentration profile in the surface layer to specify effect of metallization on the carbon diffusion and distribution of chromium concentration in the layer, for determining gradient and the diffusion depth of the element.

\section{RESEARCH SUBJECT}

A sample of Armco iron, with dimensions of $12 \mathrm{~mm} \times \varnothing 16 \mathrm{~mm}$, was applied with a chromium coating by physical vapor deposition PVD-RF. Before coating, the surface of the sample was digested in argon plasma high-frequency discharge at a pressure of $2 \mathrm{~Pa}$, auto-polarization potential $-800 \mathrm{~V}$ during 10 minutes. The process of applying a chromium coating was carried out using a pulsed DC magnetron sputtering cathodes $\mathrm{Cr}$ (Kurt Lesker) at a pressure of $0.5 \mathrm{~Pa}, 500 \mathrm{~W}$ power and potential of $50 \mathrm{~V}$ in 116 minutes. The thickness of the coating was $1.0 \mu \mathrm{m}$. The sample with a chromium coating were place in a vacuum furnace. The sample was overlaid with a chromium coating then placed in a vacuum furnace. In the first stage, the working chamber of the furnace was evacuated to a pressure of $10 \mathrm{~Pa}$ and then heated to a temperature of $1050^{\circ} \mathrm{C}$. At this temperature the sample was annealed during 60 minutes. At this time, the furnace chamber, at the same temperature dispensed gases: ethylene, acetylene and hydrogen in the volume ratio 2: $2: 1$ at a pressure of $300-800 \mathrm{~Pa}$ (pulsation) [13]. Carburizing process consisted of alternating segments of diffusion and saturation of 4/10, 2/17, 2/34, 2/31 minutes respectively. After carburizing the samples were pre-cooled to a temperature of $860^{\circ} \mathrm{C}$, soaked for 20 minutes at this temperature and quenched in a gas (nitrogen) at a pressure of 1.2 MPa to ambient temperature. The treated sample was examined in diffraction spectrometric and metallographic tests. The method used for obtaining the hybrid layer is described in a patent [2].

\section{RESULTS}

To determine the construction of the obtained hybrid layer metallographic, diffraction and a quantitative depth profile of chromium and carbon was performed.

Metallographic examination revealed the presence of a continuous layer of different morphology (Figure 1). It is visible from the surface of white layer having a thickness of about 10 to $15 \mu \mathrm{m}$, passing into the pearlitic structure, and then ferritic-pearlitic to the ferrite substrate. Samples were also tested by small angle X-ray diffraction. Diffraction was carried out using Xray diffractometer equipped with ancopper anode. The sample was scanned at $2 \Theta$ configuration, starting from an angle of 20.5 degrees and ending at 85 degrees in steps of $0.1^{\circ}$. Counting time $\mathrm{t}=10 \mathrm{~s}$. The results are provided in Figure 2 .

The results showed the presence in the outer layer of two types of chromium carbide $\mathrm{Cr}_{2} \mathrm{C}$ and $\mathrm{Cr}_{7} \mathrm{C}_{3}$.

In order to determine the depth of diffusion of chromium, quantitative depth profile of the chromium layer was carried out in a test sample. For the research glow discharge optical emission spectrometer (GDOES) was used equipped with software for creating distribution profiles of elements in the surface layer. The program allows to perform the profile to a depth of $100 \mu \mathrm{m}$. Figure 3 shows the results of analysis of the contents of chromium and carbon from the surface of the sample. Maximum concentration of chromium at the surface is about $9 \%$ by weight, and the diffusion depth of approx. 23 microns, and about 3\% carbon by weight.

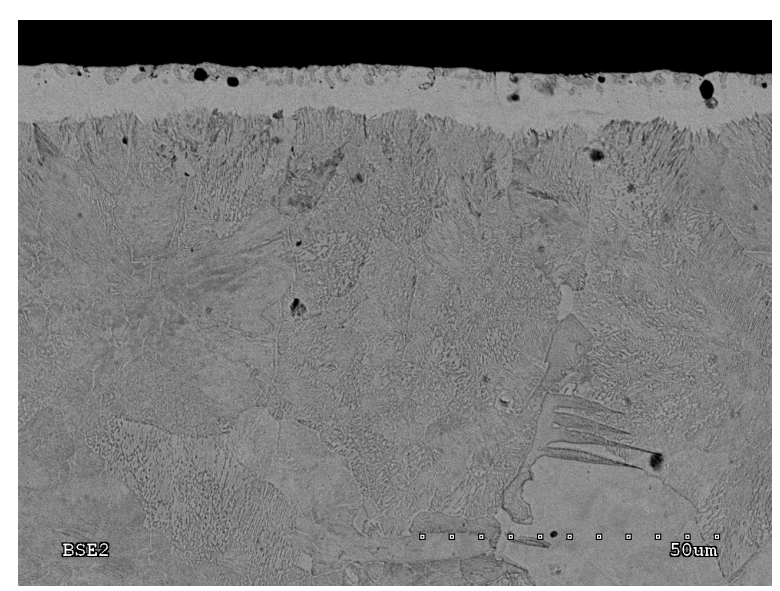

Fig. 1. The microstructure of the Armco surface after metallization and low - pressure carburizing process. Images were taken using SEM. Etching: Mi1Fe 


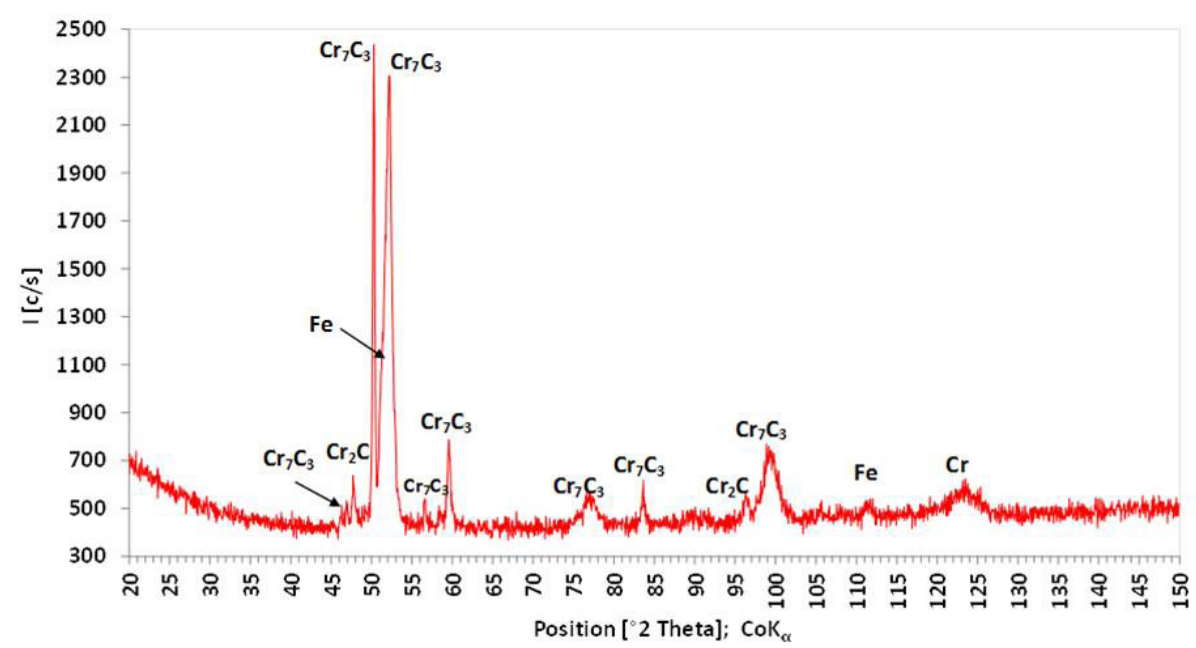

Fig. 2. Diffractogram of Armco after metallization and low-pressure carburizing process

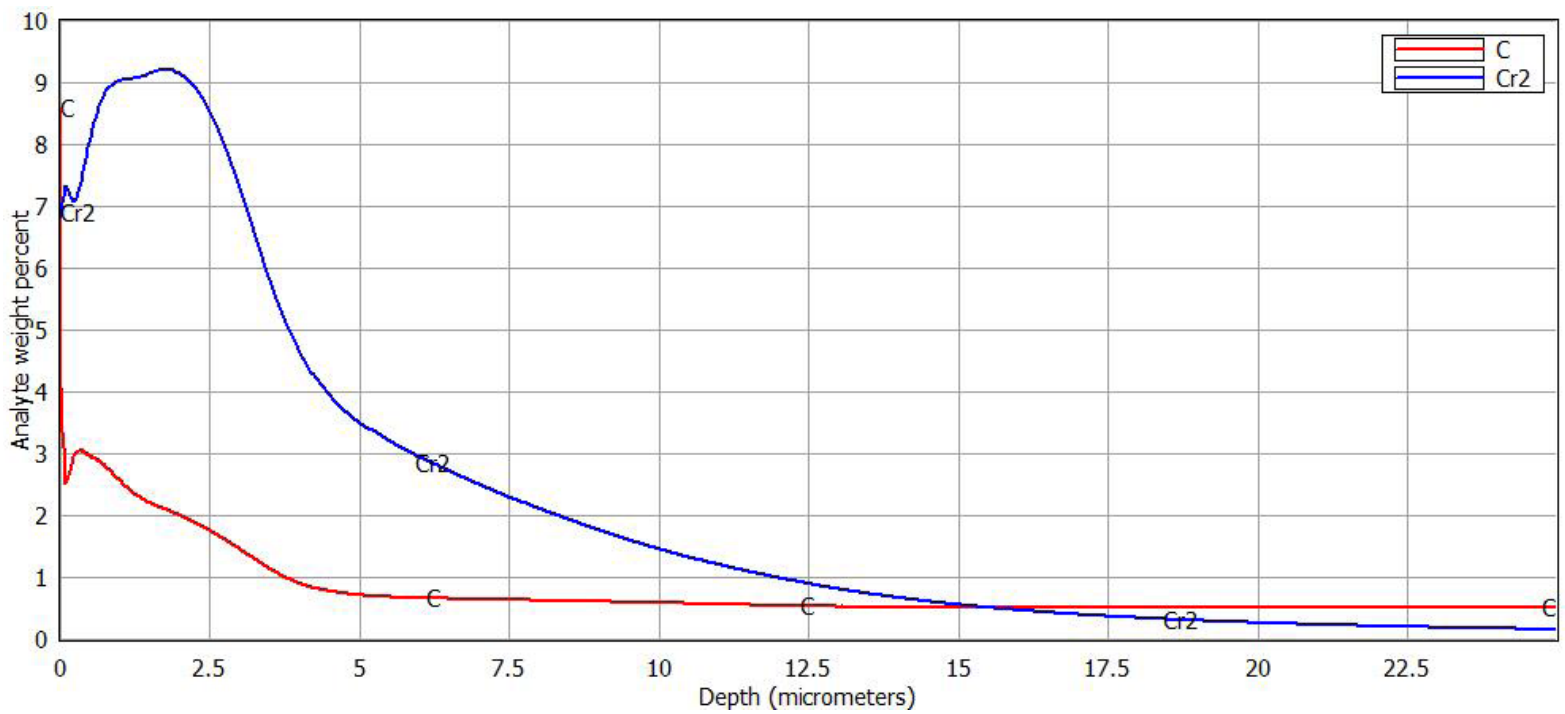

Fig. 3 Quantitative depth profile of Armco after metallization and low- pressure carburizing process

To determine the effect of chromium layer on the carbon diffusion in the carburizing concentration, the carbon profile was made in the surface layer of the test material. The measurements were made using an glow discharge optical emission spectrometer GDOES. Appointment of carbon concentration profile was based on the analyzes performed by volumetric carbon concentration at a certain depth from the surface (the depth of the crater after the firing was $2 \mu \mathrm{m})$. Another layer of material were removed mechanically by grinding abrasive papers with corundum abrasive. Based on the survey (Fig. 4) a significant carbon content at the surface can be seen, which drops sharply to about $0.5 \%$ by weight and a gentle slope to a value of $0.1 \%$ wt. The total thickness of the carburized layer made in the process is about $1.6 \mathrm{~mm}$, while the carbon content criterion for $0.4 \%$ by weight and a thickness of about $0.6 \mathrm{~mm}$. The obtained carbon profile was compared to that produced at Armco iron in the same process of carburizing without coating of chromium. Comparing the two carbon profiles it can be stated that in the case of a hybrid layer we observe the accumulation of carbon at the surface to a depth of about 10 to $15 \mu \mathrm{m}$, followed by a mild decrease in the concentration of the content in the core. However, in the case of carburizing, the result profile is characterized by a continuous carbon concentration, gradually decreasing from the surface to the core, the thickness of this layer for criterion of $0.4 \%$ by weight is about $0.8 \%$, 


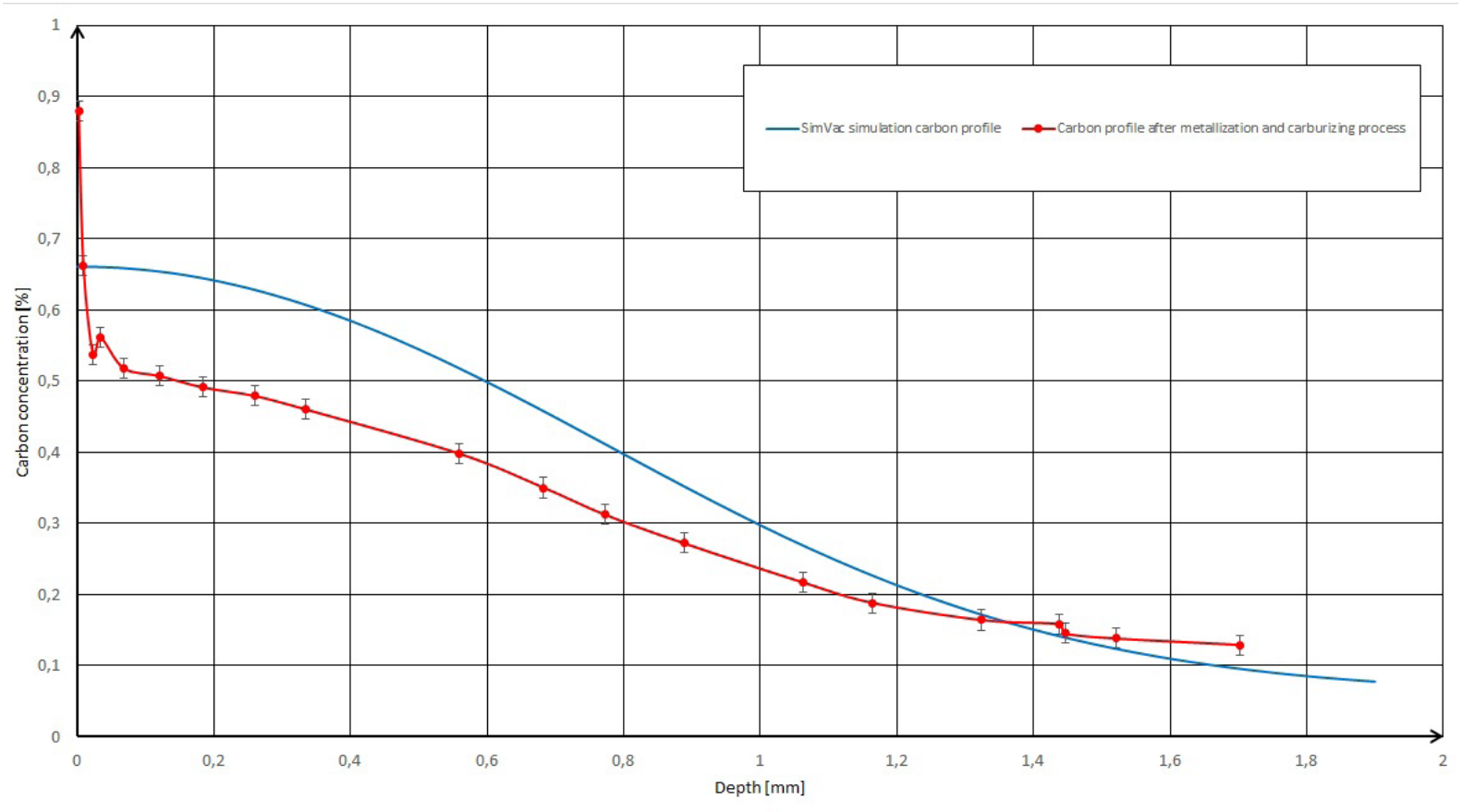

Fig. 4. Carbon profiles obtained as a result of metallization and vacuum carburizing of Armco and SimVac simulation carbon profile

while the total thickness of the carburized layer is approximately $1.8 \mathrm{~mm}$.

The research proved that:

- Carrying out the process of carburizing preceded by applying chromium coating allows a simultaneous enrichment of the element coating and carbon;

- Continuing the process obtained from the surface layer consisting of a mixture of chromium carbides $\mathrm{Cr}_{7} \mathrm{C}_{3}$ and $\mathrm{Cr}_{2} \mathrm{C}$ and carburized layer;

- Laying chromium before carburizing process reduces its amount diffused into the carbon steel, which accumulates on the surface of the resulting chromium carbides.

\section{CONCLUSIONS}

The study shows that it is possible to produce a hybrid layer, through a combination of metallization and low pressure carburizing processes. As a result of the process continuous layer of chromium carbide carburized layer on the substrate was obtained and it is consistent with the treated surface of iron core. Thus formed layer is characterized by a limited diffusion of carbon in comparison to the layer obtained by conventional carburization because it is partly used to form carbides. Such layers may have a significantly higher anti-wear attributes than the same carburized layers because of the produced intermetallic phases. These layers bring together benefits of wear resistant coatings and carburizing layers, while providing a very good cohesion of the treated substrate.

\section{Acknowledgments}

The research was carried out under the grant for statutory activities of the Institute of Materials Science TUL 2016 verification study for the modernization of its own testing procedures SUB No. 501-11-7-1-9175.

\section{REFERENCES}

1. Chen F. S., Lee P. Y. and Yeh M. C.: Thermal reactive deposition coating of chromium carbide on die steel in a fluidized bed furnace. Materials Chemistry and Physics, 53, 1998, 19-27.

2. Dybowski K., Kowalczyk P., Atraszkiewicz R. and Januszewicz B.: Patent Application No. P. 416797, 2016.

3. Esteve J., Romero J., Gómez M. and Lousa A.: Cathodic chromium carbide coatings for molding die applications. Surface and Coating Technology, 188-189, (2004), 506-510.

4. Gawroński Z., Malasiński A. and Sawicki J.: Elimination of galvanic copper plating process used in hardening of conventionally carburized gear 
wheels. International Journal of Automotive Technology, 11 (1), 2010, 127-131.

5. Gawroński Z., Sawicki J.: Technological surface layer selection for small module pitches of gear wheels working under cyclic contact loads. Materials Science Forum, 513, 2006, 69-74.

6. Gold M., Zeigler D. D., Harth G. H., Tanzosh J. M., LaCount D., Kung S. C. and Mohn W. R.: United State Patent No.: 6503340, 2003.

7. Kessler O. H., Hoffmann F.T. and Mayr P.: Combinations of coating and heat treating processes: establishing a system for combined processes and examples. Surface and Coating Technology, 108 (1), 1998, 211-216.

8. Kessler O.: Combination of coating and heat treatment processes, Surface and Coating Technology, 201, 2006, 4046-4051.

9. Kula P, Kaczmarek Ł, Dybowski K, Pietrasik R and Krasowski M.: Activation of carbon deposit in the process of vacuum carburizing with preliminary nitriding. Vacuum, 87, 2013, 26-29.

10. Kula P., Pietrasik R., Dybowski K., Paweta S. and Wolowiec E.: Properties of surface layers processed by a new, high-temperature vacuum carburizing technology with prenitriding - PreNitLPC®. Advanced Materials Research, 401 (6), 2012, 452-453.

11. Kula P., Olejnik J., Heilman P.: European Patent No.: EP1558780, 2007, United States Patent No.: US 7513958, 2009.

12. Ramqvist, L. H., Grinder N. O., Sporrong M., Enghang P.: United State Patent No. 4013487, 1997.

13. San S.: A study on kinetics of CrxC-coated highchromium steel by thermo-reactive diffusion technique, Vacuum, 79, 2005, 63-70.

14. Sawicki J., Górecki M., Kaczmarek Ł., Gawroński Z., Dybowski K., Pietrasik R., Pawlak W.: Increasing The Durability Of Pressure Dies By Modern Surface Treatment Methods. Chiang Mai Journal of Science, 40 (5), 2013, 886-897.

15. Wierzchon T.: Structure and properties of multicomponent and composite layers produced by combined surface engineering methods, Surface and Coating Technology, 180-181, 2004, 458-464. 